no one could speak with more authority on this subject than Sir Robert Hadfield himself.

The new laboratory has been equipped more particularly for research on corrosion and its prevention. For this purpose it is provided with large corrosion tanks of varying design and with other equipment not usually found in a chemical laboratory. At one end is a dark room containing a magnificent micrographic apparatus purchased with the aid of a grant awarded by the Government Grant Committee of the Royal Society to the head of the Chemistry Department in order to enable him and his research students to study the micrography of corrosion.

As Sir Robert wisely pointed out, the object of a school laboratory is different from that of a works laboratory. The latter is designed to turn out material results; the former is primarily intended for training the men, so that when they pass into industry they will know how to tackle their problems along the most approved lines.

As a further inducement to research three prizes for theses have been offered, namely, one each by Sir Robert Hadfield, the Dunlop Rubber Company, and the Mond Nickel Company respectively. It is hoped that manufacturers and students alike will avail themselves to the full of the new facilities. It is only by the closest co-operation between science and industry that we can hope to capture that portion of the world's trade which is so essential to our national existence. J. N. F.

\title{
Aeroplane Performances.
}

COMPARISON of the "Wren" light plane with recent U.S.A. Navy racing and fighting aeroplanes shows the price of speed in a definite way. The following table gives some of the more significant figures :

\begin{tabular}{|c|c|c|c|c|}
\hline Name. & Power. & Speed Range & Total & Lifting \\
\hline ren & $4 \frac{1}{2} \mathrm{kw}$. & $25 / 12 \cdot 5=2$ & I75 kg. & II $\mathrm{m}^{2}$ \\
\hline A. sea-racer . & . $350 \mathrm{kw}$. & $90 / 34=2 \cdot 6$ & $1000 \mathrm{~kg}$. & $13.5 \mathrm{~m}^{2}$ \\
\hline S.A. land-racer & . $350 \mathrm{kw}$. & $112 / 33=3.4$ & $900 \mathrm{~kg}$. & $\mathrm{I}_{4} \cdot 5 \mathrm{~m}^{2}$ \\
\hline U.S.A. land-fighter & $300 \mathrm{kw}$. & $76 / 27=2.8$ & r250 kg. & $24.5 \mathrm{~m}^{2}$ \\
\hline
\end{tabular}

The racers have less surface than many of the light planes at Lympne, and the bodies are of the same order of length and cross-section, and show the same scrupulous cleanness of line. To pass from the Wren to the racer, about eighty times the power has been concentrated within the limits of an external surface scarcely distinguishable by the layman from similar types of light plane. The speed obtained is about four and a half times greater. Thus the power required is approximately as the cube of the speed.

This rule is even more accurate in comparing the seaplane with the landplane at the fine incidences occurring at the upper limit of their wide speed ranges. It may be inferred, therefore, that the floats cost half the total power available $\left(90 / I_{12}\right)^{3}$, in spite of some sacrifice of the lower limit of speed (landing speed), by reduction of surface. The essential inferiority of the seaplane is evident.

In the land-fighter, the inclusion of machine-gun equipment and the reduction of the all-important landing speed to $27 \mathrm{~m}$./s. is obtained by roughly doubling the surface, and sacrificing one-third of the racer's speed, equivalent to about two-thirds of the power.

Great range of speed is always an index of very large margin of power, and therefore of high rate of climb, at sea-level, falling off with height and density, and finally of a high "ceiling " or limit of height attainable.

Assuming liberally in the case of the racer that $100 \mathrm{kw}$. is required for level flying at $40 \mathrm{~m}$. $/ \mathrm{s}$. near sealevel, this leaves $250 \mathrm{kw}$. for climbing. Taking the airscrew efficiency as 0.7 and $g$ as $9.81 \mathrm{~m} . / \mathrm{s}^{2}$, this gives an initial climb of $0.7 \times 250 \times 1000$ watts $/ 900 \times 9.81$ m.kg.s. ${ }^{-2}=20 \mathrm{~m} . / \mathrm{s} .=\mathrm{I} \cdot 2 \mathrm{~km} . / \mathrm{min}$. To calculate the ceiling height with any accuracy much more precise data are required.

The official height record, of $10.75 \mathrm{~km}$. at this date, rests with France, but the same pilot, M. Sadi Lecointe, has since claimed over II km. A U.S.A. claim, not officially accepted in the absence of sufficient control, gives an altitude of $12.5 \mathrm{~km}$., which would mark the invasion by man of the heights of the stratosphere.

\section{The Floor of the North Sea. ${ }^{1}$}

THE report on the marine deposits of the south part of the North Sea, referred to below, may be characterised as being long overdue, since it is founded on about 600 samples taken by the Marine Biological Association's steamers in 1904-8, when that Society was undertaking the English share of the International investigations. How extraordinarily efficiently that share of the work was done is illustrated by the reports published on the collections and material and in the peculiar discrimination shown in the selection of these samples. It is common knowledge that much of the substance of this report was known to the Admiralty during the War, proving of value in respect to navigation in foggy and other difficult weather. The area treated, the North Sea roughly from the latitude of the Scottish border to the Straits of Dover, is an exceedingly difficult one on account of the complexity of its past geological changes and the variety of its currents, whether produced by wind or other means, acting in a comparatively shallow sea, much broken by banks (especially in its western parts) and intersected by 1 Ministry of Agriculture and Fisheries, Fishery Investigations. "The Marine Deposits of the Southern North Sea." By J. O. Borley. (H.M.S.O. I5s. 1923.)

$$
\text { NO. } 28 \text { I9, VOL. I I } 2]
$$

pits and troughs, of which the Dogger Bank, depth 7. fm., and the Silver Pit, $5^{6} \mathrm{fm}$., may be mentioned.

The samples were taken out of the material collected by a conical dredge with bag dragged along the bottom and thus selected at each haul out of a considerable quantity of deposit. The colour of the sample was carefully noted, and a series of illustrations of representative samples, showing colour and texture, is published; they are a little hard, as is inevitable with all colour-process work as compared with lithography. The estimations of the amounts of the various grades (determined by least diameters of contents) of gravels, of sands, and of silt were done quantitatively, mainly by means of a special levigating apparatus designed by the author of the report under notice. The different grades after drying and weighing were then examined and their mineral and other contents noted. The absence of the organisms of decay from the samples, which were usually of about $2 \mathrm{~kg}$. weight, was interesting, worms being found still alive after 17 months in the bottles. The percentage present of each sized grade in a sample, having been carefully taken, is multiplied by 
the diameter factor of the grade (least diameter in $\mathrm{mm}$.) and divided by Ioo, so as to determine the "representative number" of the sample.

The advantage in this technique lies in the fact that the numbers increase roughly in accordance with the increased coarseness of texture of the bottom. The whole method shows a great advance in that it eliminates so far as possible human judgment. It only remained to chart the grounds in accordance with these " representative numbers," this being the basal chart, and then in respect to the percentages present of the grades it was desired to consider especially closely. This has been done in a series of twelve singularly informative charts, which are substituted for the interminable text-descriptions of many authors, a most welcome innovation here with little real loss of matter. The basal chart shows a considerable series of very irregular areas, especially numerous and irregular towards the English coast, and the rest represent the kind of analysis of the jottom material such as would be necessary for the understanding of the conditions, currents and other that produced these areas. The text shows the actual organic and mineral constituents present in each type of ground.
Thus, while the report is eminently useful to the practical fisherman in his navigation in foggy weather and in telling him about the ground on which he is shooting his nets-each kind of ground is correlated with the abundance or rarity of different species of fish-it constitutes the publication of a research of basal importance in respect to the general erosion of the eastern coasts of England. The bottom, while influenced by land material off each estuary, shows the more gradual passage from the stones or coarse gravels of the English coast to the fine silt of the centre and to the continental sands. The causes of this distribution, so far as present knowledge goes, are attractively discussed-attrition, the grade of material kept in motion by different strengths of currents, the correlation of the areas with the currents as known by independent observations of both surface and bottom movements, and so on.

To conclude, this publication is a practical fisheries report and at the same time a research of very great scientific importance, embodying novel methods of treatment of knowledge and suggesting many further lines of research; the Ministry of Agriculture and Fisheries is to be heartily congratulated on its appearance

\section{The Physicist in the Textile Industries. ${ }^{1}$}

THE development of the textile industries has been one of the greatest factors in civilisation, but it has been said that the great weakness of the cotton industry - and this applies equally to the other textile industries--is that it is not using to the full the immense powers bestowed on this generation by scientific discovery. In the mill, perfection of manipulation seems, at first glance, to have been attained. It may be said that, if such skill can be developed in the past without the aid of the physicist, then there is no need for him, and this, no doubt, is the attitude of some people whose conservatism still holds them members of the "rule of thumb" school. It is impossible not to admire what has been achieved by such methods, but at the same time one cannot help but wonder what advantages might have been gained had the great skill of the operative been united with the insight of a trained scientific mind. For example, if an attempt is made to probe the inner functions of any of the complicated, or simpler, machines, one soon finds how little is really known about the treatment to which the material is being subjected. On inquiry, varieties of explanation are offered, each, no doubt, a carefully weighed opinion, but still, only an opinion. The reason is that many of the investigations that have hitherto been made took place under vaguely defined, and, therefore, unscientific conditions, with the result that other experimenters have held contrary views, and valuable time has been wasted.

Might not the application of scientific methods settle such controversial matters, and possibly in the end lead to improved machines? There is no question of decrying the ability of the skilled operative; his skill based upon years of mill experience can never be attained by a man whose younger years have been spent in training for scientific work. Undoubtedly the duties of scientific workers are complementary to those of the operative. Here lies the opportunity of the physicist-- to bring scientific method into the testing rooms, and even into the mill, in order to ensure that tests made upon the various products of the different machines shall be comparable with those obtained at other times, either on the same or similar machines.

1 Synopsis of a lecture delivered before the Institute of Physics on October 22 by Dr. A. E. Oxley.
The textile industries offer an almost entirely unexplored and unlimited field for the research physicist, and it is not a question of searching for a problem worthy of investigation, but one of selecting, from the great number of attractive problems presented, a few which shall form the most trustworthy basis on which to build a secure foundation for the development of a progressive research programme. It should be remembered that physical research in the textile world is by no means in such an advanced state as it is in the metallurgical world. Although in the textile industries many of the research problems are of a physical nature, and all have a physical aspect, the number of physicists engaged is only about twenty. A brigade of trained physicists would be more in proportion to the problems urgently awaiting solution. It is safe to say that there is no other industry so much in need of co-operation with the physicist as is the great textile group.

There is one outstanding factor which must be brought to the notice of the physicist contemplating textile research, and this applies to textile materials in general. The material he has to investigate is generally of a most disturbing character on account of its variability. The result is that a very careful selection or sampling of the test specimens must be made, and in many cases very laborious series of tests are needed before a result representative of the bulk, which is the only material recognised by the manufacturer, can be obtained. This fact differentiates rather sharply the physicist of textile research from the physicist in other industries.

Slides were shown by the lecturer to illustrate the types of research on which the textile physicist is engaged. These included investigations on (I) rigidity of the single fibre, a property of fundamental importance in spinning; (2) sorting of samples $(a)$ to examine the various fibre lengths in pure cottons or mixings, and $(b)$ to detect what damage, if any, is caused to the fibres by the different machines; (3) regularity of threads, a property of great importance in the production of threads for weaving fabrics of fine structure; (4) oscillation stresses on threads such as are met with in weaving; and (5) the measurement of the lustre in finished threads and fabrics and the relation of lustre to doubling twist. 